\title{
The Rhetorical Structure of Preface Sections in Textbooks: Variations across Disciplines
}

https://doi.org/10.33806/ijaes2000.21.2.9

\author{
Hmoud S. Alotaibi \\ Shaqra University, KSA
}

\begin{abstract}
The present study investigated disciplinary similarities and differences in the rhetorical structure of 120 preface sections drawn from three soft disciplines, namely applied linguistics, business administration, and law, as well as from hard disciplines, namely computer sciences, chemistry, and biology. While the overall results showed a fivemove structure, some disciplines emphasized the use of particular moves. The Announcing objectives and Outlining organization moves were obligatory in all disciplines, while the Establishing the needs of the readership move was more predominant in business administration, law, and biology prefaces. The Identifying audience move was more common in computer science prefaces, and finally the Acknowledging contributions move was more frequent in computer sciences and law prefaces. The study also investigated other features used in the prefaces and the frequency with which they occurred in different fields. The study concluded with a recommendation to conduct similar genre-based studies to help clarify the disciplinary variations in the preface sections.
\end{abstract}

Keywords: Genre, rhetorical structure, discipline, textbook, preface

\section{Introduction}

Textbooks are an essential genre in academia, and thus academics are encouraged to be fully cognizant of their use. This knowledge can be attained by learning the conventions of this genre and all its associated sub-genres such as the preface. Alotaibi and Arabi (2020) argued that "knowledge construction can be shown through move structure proposed in the CARS (Create a Research Space) model (Swales 1990, 2004)" (p. 42). Kuhi (2008) cogently addressed the mediating participants of textbook discourse, namely the author, the student, the teacher, the publisher, and the peer colleagues (p. 75). He emphasized that the awareness of this multiple participant relationship that underlies the move structure of the preface subgenre is crucial. (p. 76). As pointed out by Mohsenzadeh (2013), "Prefaces are important because they help the reader to have an overview of the book, to get some information about the different parts of it, and thus to decide which parts correspond to their purpose in mind and worth reading" (p. 318). Despite this importance, book prefaces are underresearched. As pointed out by Mohsenzadeh (2013), "it seems that the existing literature suffers from a gap in genre studies which is related to the fact that introductory genres such as book prefaces have been left untouched" ( $p$. 318). 
The present study attempts to fill this research gap by examining textbook prefaces in a range of academic disciplines. To fulfill the objective of the study, the following research question is addressed:

What are the similarities and differences in textbook prefaces in three soft disciplines, namely applied linguistics, business administration, and law as well as in three hard disciplines, namely computer sciences, chemistry, and biology?

\section{Literature review}

The previous studies that examined textbook prefaces relied on the genre approach of Swales (1990) and Bhatia (1993). Luzón (1999) examined the generic structure of 22 textbooks from computer engineering and telecommunications engineering fields. The author found the use of eight rhetorical moves: (1) Stating the purpose and the intended scope; (2) Description and justification of the elements included in the text; (3) Explanation of terms and conventions used in the book; (4) Describing the audience; (5) Origin of the book and justification for writing the book; (6) Instructions on how to use the book; (7) Description of the content of each chapter; and (8) Acknowledgments. The author emphasized that the preface sections of textbooks had promotional goals. Some moves noticeably included promotional purposes such as Description and justification of the elements included in the text, Describing the audience, Origin of the book and justification for writing the book, and Acknowledgments.

Kuhi (2008) examined the schematic structure of preface sections in the field of applied linguistics. The corpus included 21 textbooks, and the author identified a four-move structure, namely Announcing Objectives, Identifying Audience, Outlining Organization, and Acknowledging Others' Contribution. The first two moves appeared in all texts, while the third move appeared in only 14 texts, and the fourth move occurred in 17 prefaces.

Similarly, Azar (2012) investigated the move structure of 22 textbook prefaces in two related fields, linguistics and applied linguistics. The analysis detected a four-move schema, namely Move 1 (Establishing the needs of the readership); Move 2 (Establishing orientations); Move 3 (Introducing chapters and scope); and Move 4 (Acknowledgements). Move 2 (Establishing orientations) was attained through one or both of the following steps: Purpose and Announcing audience. Move 1 and Move 2 were the most dominant moves in the texts. Move 3 was used in 17 out of 22 textbooks, and finally Move 4 was the least to be employed as it appeared in only 10 out of 22 prefaces. In addition, Azar found that the authors promoted their textbooks through "appealing to a potential readership, talking to their readers and bringing them into the texts by using positive adjectives extensively, presenting positive attitudes and intentions towards their work using stance features like self-representation markers and boosters" (pp. 161-62). Hence, Azar argued that such features clearly reflect the promotional intentions of the 
authors of textbook prefaces. The promotional tendencies were also found in Ji and Wang (2016). The authors examined diachronic changes of the university textbook prefaces in China from 1966 to 2010. They found that between 1966 and 1980, the university textbook prefaces were "objective, conservative and monotonous in design" (p. 15). However, between 1996 and 2010, they highlighted that "new promotional moves and steps emerged and became increasingly visible" such as justification of writing aims and establishing credentials moves. (p. 15).

Furthermore, Abdollahzadeh and Salarvand (2013) analyzed the generic structure in 180 English academic electronic books published between 2000 and 2011 from three disciplines: management, metallurgy and mathematics. The overriding schematic structure had seven moves: Move 1 (Introducing the work), Move 2 (Specifying the purpose), Move 3 (Describing the book), Move 4 (Identifying the readership), Move 5 (Referring to other related sources), Move 6 (Eliciting a response), and Move 7 (Expression of gratitude). The Moves 1, 3, 4, and 7 included sub-moves or steps. The results showed that there was no significant difference among the three sets of discipline prefaces in terms of the frequency of moves and the available steps in them. The authors argued that this similarity "suggests that book prefaces in these three disciplines belong to the same genre and are rather similar in terms of other significant factors such as the communicative purpose(s) or reader's expectation and demands " (p. 1624). In addition, the authors found that there was also a similarity in the three groups of prefaces in terms of using rhetorical functions to promote the status of the book. Similar to the use of rhetorical functions, the authors found a comparable use of linguistic features such as imperatives and second person pronouns, which have persuasive and promotional effects. This last finding about promotional intentions correlates with Azar's (2012) and Ji and Wang's (2016) findings, outlined above. Asghar, Asghar, and Mahmood (2015) used the move structure proposed by Abdollahzadeh and Salarvan (2013) to investigate the rhetorical structure of 15 preface sections in linguistics textbooks. The obligatory moves were only three: Introducing the work, Describing the book, and Expression of gratitude. Despite this similarity, the authors found that the distribution of the other moves varied from one textbook to another.

The role of culture and language was also investigated in the genre of textbook prefaces. Mohsenzadeh's (2013) study shed light on the move analysis of 40 literature book prefaces in English and Persian. The move called General statement/description was the only common main move between English and Persian book prefaces. Hence, it "seems that the authors of both languages are aware of the fact that providing their readers with a background will help them in better comprehension of the text" (p. 322). Specifically, the moves that were found prevalent in English literature prefaces with their frequencies were Move 1 (General statement/description) (75\%), Move 2 (The significance) (40\%), Move 3 (The purpose) (90\%), Move 4 (Type of reader) (55\%), Move 5 (Information about the 
chapters or other volumes) (60\%), and Move 6 (More explanation) (55\%). On the other hand, the frequent moves in Persian prefaces were Move 1 (Significance) (65\%), Move 2 (The purpose) (40\%), Move 3 (Type of reader) (50\%), Move 4 (Chapter description) (30\%), Move 5 (General statement or description) $(80 \%)$, Move 6 (Shortcomings) (40\%), Move 7 (Acknowledgement) (60\%), and Move 7 (Hope expression) (40\%). Therefore, the major two salient features in the Persian group prefaces were that they a) addressed shortcomings in their works and b) used quotations from famous people and Arabic expressions, which according to the author reflects their culture (p. 322).

Following the same line of research, Al-Zubaidi and Jasim (2016) examined 80 preface sections in linguistics textbooks written in English and Arabic. The most common move structure across the two languages consisted of three moves: Heading, Identifying the organization of the book, and Signing off. Some moves were found to be more common in the Arabic group compared to the English group such as the Opening and Closing moves. This variation clearly indicates that the move structure of preface textbooks can vary across cultures. Specifically, the authors found that there was an extensive use of religious expressions in the Arabic corpus such as prayers and invocations. In addition, the Arabic authors showed a tendency to use academic titles in the Singing off move while their English counterparts preferred to use their first names without titles.

A more recent investigation looked at the use of metadiscourse, by using Hyland's (2005) taxonomy of interactive and interactional categories. Munalim and Lintao (2016) compared book prefaces by 15 Filipino authors and 15 English authors and found that in both language groups the interactional resources (viz. self mentions, hedges, boosters, and attitude markers) were more frequent than interactive categories (viz. transitions, frame markers, and code glosses).

This short review of the literature suggests that the picture is still unclear in terms of the move structure of preface sections in textbooks. While some studies found similarities across disciplines (e.g. Abdollahzadeh \& Salarvand, 2013), Kuhi (2008) and Azar (2012) examined one discipline, viz applied linguistics, and reported conflicting results. The present study thus sheds light on disciplinary variations and similarities by focusing on a large number of academic disciplines.

\section{Methodology}

The corpus comprises 120 preface sections of textbooks in six academic fields, with 20 prefaces from each field. Three fields belong to the soft disciplines category, namely applied linguistics, business administration, and law. In addition, three fields belong to the hard disciplines category, namely computer sciences, chemistry, and biology. The examined textbooks were published over a period of ten years (1999-2019). Specialists in each field have provided help in recommending the textbooks to consider for analysis. 
Before doing the analysis, the researcher read the entire preface sections to gain a general idea about the appropriate rhetorical structure. Hence, it was found that Kuhi's (2008) and Azar's (2012) models were the most appropriate analytical frameworks. Each model in these two studies consisted of four moves; however, to have a more comprehensive model, the researcher made a slight modification that resulted in a five-move structure, as outlined in Table 1.

Table 1. The rhetorical structure of preface sections in textbooks

\begin{tabular}{|c|c|c|}
\hline $\begin{array}{l}\text { No. of } \\
\text { moves }\end{array}$ & Moves & Functions \\
\hline Move 1 & $\begin{array}{ll}\text { Establishing the } \\
\text { needs of the } \\
\text { readership }\end{array}$ & 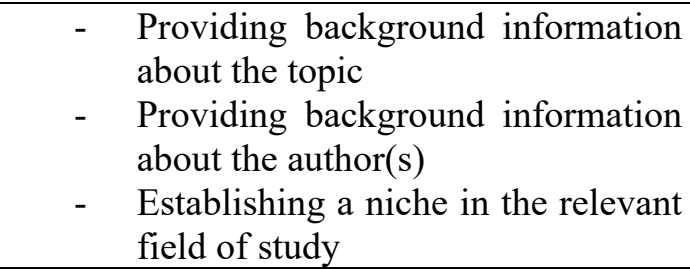 \\
\hline Move 2 & $\begin{array}{l}\text { Announcing } \\
\text { objectives }\end{array}$ & $\begin{array}{l}\text { - Highlighting the purpose(s) of the } \\
\text { study }\end{array}$ \\
\hline Move 3 & $\begin{array}{l}\text { Identifying } \\
\text { audience }\end{array}$ & $\begin{array}{l}\text { - } \begin{array}{l}\text { Specifying the potential readers } \\
\text { directly or indirectly }\end{array} \\
\end{array}$ \\
\hline Move 4 & $\begin{array}{l}\text { Outlining } \\
\text { organization }\end{array}$ & $\begin{array}{ll}\text { - } & \text { Highlighting the scope of the book } \\
\text { - } & \text { Discussing the content of the book } \\
\text { - } & \text { Naming the chapters and sections }\end{array}$ \\
\hline Move 5 & $\begin{array}{l}\text { Acknowledging } \\
\text { contributions }\end{array}$ & $\begin{array}{l}\text { - Thanking those who have helped } \\
\text { the person during the course of the } \\
\text { work } \\
\text { - Thanking family members for their } \\
\text { support and patience }\end{array}$ \\
\hline
\end{tabular}

The analysis was conducted by the researcher, and the results were verified by an expert in the field who had publications in genre-based studies, especially with rhetorical analysis. Each preface was given an identifying number, and then the moves were coded. In the results section, the extracts will be followed by the name of the discipline as well as the number of the preface in the list, out of 20 in each discipline.

\section{Results}

\subsection{The rhetorical structure in the preface sections}

The examination of the rhetorical structure of preface sections in a range of academic disciplines yielded a five-move structure. When grouping the disciplines into soft vs. hard categories, the use of each move appeared almost identical, as shown in Table 2. 
Table 2. The rhetorical structure in textbook prefaces of soft and hard disciplines

\begin{tabular}{|l|l|l|l|l|l|}
\hline & Move 1 & Move 2 & Move 3 & Move 4 & Move 5 \\
\hline Soft & 49 & 55 & 40 & 58 & 35 \\
\hline Hard & 49 & 56 & 43 & 58 & 37 \\
\hline
\end{tabular}

As outlined in Table 3, the analysis showed that Move 2 (Announcing objectives) and Move 4 (Outlining organization) were the most commonly used moves across disciplines. The rest of the moves, however, displayed some discrepancies. Move 1 (Establishing the needs of the readership) was more frequent in business administration, law and biology prefaces, Move 3 (Identifying audience) was more predominant in computer science prefaces, and finally, Move 5 (Acknowledging contributions) was more frequent in computer sciences and law prefaces.

Table 3. The distribution of moves in textbook prefaces

\begin{tabular}{|l|l|l|l|l|l|}
\hline & Move 1 & Move 2 & Move 3 & Move 4 & Move 5 \\
\hline AL & 13 & 18 & 14 & 19 & 11 \\
\hline BA & 19 & 20 & 14 & 19 & 8 \\
\hline LAW & 17 & 17 & 12 & 20 & 16 \\
\hline CS & 14 & 17 & 17 & 20 & 17 \\
\hline Chem & 16 & 20 & 14 & 19 & 9 \\
\hline Bio & 19 & 19 & 12 & 19 & 11 \\
\hline
\end{tabular}

\section{Move 1: Establishing the needs of the readership}

The investigation into the use of Move 1 has shown that it is almost obligatory in three disciplines, namely business administration, law, and biology. In the other disciplines, however, Move 1 appeared to be less common. Writers used this move generally for two purposes. First, and most commonly, was to provide a background knowledge about the topic, as exemplified in example (1), and (2). In example (1), the author of the book An Introduction to English Semantics and Pragmatics started by discussing the relationship between pragmatics and semantics. These introductory statements helped the author to introduce the purpose of his book by showing that it is an integration of both fields. The author in example (2) began the preface by discussing the history of parasitology in relation to other branches of sciences, namely medical and basic sciences, before he announced the title of the book Molecular Medical Parasitology.

(1) Pragmatics deals with inferences that listeners and readers make, or that - when speaking or writing - they invite others to make. These inferences are often conscious, so pragmatics tends to be easier to understand than semantics, because the latter is about abstract potential meanings that are 
often best described by means of notations drawn from logic and set theory. Linguistic meaning cannot usefully be studied by someone who knows only about pragmatics, however. A view widely shared among linguists is that semantics and pragmatics are essential components that work together in a full description of meaning. In this book, I attempt to integrate semantics with pragmatics, but I hold back a detailed exposition of pragmatics until near the end... (AL 2)

(2) Parasitology was born as the tropical stepchild of medicine but has become a well recognized scientific and medical discipline in its own right in our increasingly globally conscious world. It began as a descriptive medical curiosity but the remarkable adaptive mechanisms evinced by these astoundingly versatile organisms have stimulated significant research. Many advances in basic science have come from the study of this increasingly fascinating, phylogenetically diverse group of organisms. Parasitology, in the past decade, has undergone another consequential metamorphosis. The entry of molecular biology with its elucidation of the genetics, genomics, and proteomics of these organisms has provided increasingly sophisticated explanations of their capacities to persist under intense ecological and physiological pressures. Molecular Medical Parasitology had its inception in an earlier volume entitled... (Bio 6)

Second, Move 1 functionally served to establish the need for the book. The author in example (3) began the preface by showing that the first edition of the book was successful and was well received by readers and critics, and the second edition is therefore timely and essential. He concluded Move 1 by showing that the new edition would be of interest, and to convince readers, he used the boosting device undoubtedly. Similarly, the authors in example (4) showed that their book is needed to fill a gap in the literature. In example (5), the authors used the transition marker therefore as a logical conclusion to fill the gap they pointed out in the previous sentence, which showed the need for multidisciplinary approaches. In example (6), the authors firstly showed that there was only one book on the topic, and by using the attitude marker unfortunately, they showed it is not available for readers. Secondly, they criticized the book by using a strong the statement suffers from two major drawbacks. Generally, the authors have utilized this move for promotional intentions. As displayed in example (7), the author raised the question of the need for the textbook, and answered it by using the boosting device absolutely, which clearly manifests the promotional and persuasive intention.

(3) While there was and is some literature on the subject, it did not and does not have an adequate academic orientation or was not or is not sufficiently specialized in the institutional field. [...] The fact that the first edition sold out and is out of print was also a consideration for doing a second edition at this point in time. [...] I was in no small measure encouraged to undertake this second edition by the positive reviews given to the original book, not to 
mention the fact that the first edition was well received and acclaimed in academia and among professional international lawyers and administrators. It should undoubtedly continue to be of use and interest alike to academics, practitioners and students both graduate and undergraduate. (Law 18)

(4) For a long time, a reference/textbook has been needed which provides detailed information on the synthetic routes to a wide range of energetic materials. The objective of this book is to fill this gap in the literature. (Chem 10)

(5) Given these complexities, multidisciplinary approaches are needed to address environmental pollution issues. Therefore, this text provides a rigorous science-based integration of the physical, chemical, and biological properties and processes that influence the environment and that also affect contaminants in the environment. (Bio 19)

(6) Unfortunately, this specialist literature is not easily accessible to newcomers to the field. For many years the book by Moss, Advanced Molecular Quantum Mechanics (1973), served as an introduction to the field, but today this book suffers from two major drawbacks - it is out of print and it does not cover the developments of the past three decades. We therefore decided that there was a need for a book to fill the gap between the standard texts on quantum mechanics, which have little if anything on relativity, the advanced texts, which treat relativity in detail but have little connection with quantum chemistry, and the literature, where there is a large amount of both theory and applications. (Chem 15)

(7) Is there still a need, then, for a book such as the one you hold in your hands? Absolutely! Regardless of how complex or complicated database management becomes, there will always be a need for a book on the basics of database design. You must learn the fundamentals in order to know how and why things work the way they do. (CS 16).

\section{Move 2: Announcing objectives}

Move 2, where writers announce the objectives and purposes of their book, was commonly employed in all disciplines. It was used in all preface sections in business administration and chemistry books, in 19 preface sections in biology, and in 18 prefaces in applied linguistics. Finally, it was used in 17 prefaces in law and computer science books.

Writers announced the objectives of their books by using a passive structure which showed the employment of the verb intend as exemplified in example (8) and in example (9) where the authors pointed out the objective of the book indirectly. More frequently, however, the authors, as in example (10), used the noun phrase this textbook followed by a verb that highlights the aim of the book. In this example it is focus, and in this case the authors announced the objectives of the 
textbooks by showing the nature of the book instead of employing key terms such as objective, goal, and aim.

(8) This book is intended to present a broad picture of dynamic games in economics. (BA 2)

(9) The book is not intended as an introduction to phonological theory; some books of that sort are listed in the Suggested Further Reading. Inevitably, I have had to draw on notions proposed in various theoretical frameworks. Any proposed distinction between theory and description is fraught with difficulties: there can be no description without theoretical assumptions, as the philosopher of science Karl Popper pointed out. However, in my view, some kind of distinction between theory and description must be upheld. My aims here are primarily descriptive. (AL 4)

(10) This textbook focuses on: (i) the continuum of the environmentnamely the earth, water, and atmosphere, epitomized by the term "Environmental Science"; and (ii) science-based aspects of the pollution of the environment. Thus, this textbook is designed to provide a scientific basis that will allow for prudent decisions to be made to manage and mitigate pollution throughout the environment. (Bio 19)

\section{Move 3: Identifying audience}

The employment of Move 3 varied across the disciplines. It was used the most in computer science prefaces with 17 cases, followed by 14 prefaces in applied linguistics, business administration and chemistry. The biology and law prefaces appeared to be the least to employ this move, with 12 prefaces. The major strategy was the announcement of audience explicitly. This could be attained through key terms such as intend and designed, as in example (11) and example (12), respectively. In example (11), the move emphasized the target audience by repeating the word intended and showing that the textbook was for beginners in historical linguistics with a limited background in this topic. In example (12), the promotional intention is clearly manifested, as the author showed that the textbook was designed to meet CAA's accreditation standards for law courses in undergraduate and graduate programs. In example (13), the authors delayed the identification of audience until after they discussed the organization of the book. Therefore, the lexical category employed here was expression of hope. In example (14), the author used engagement markers to speak to one audience (i.e. practitioners) for his philosophical underpinnings in the book to show they were used to help another group of audience (i.e. students).

(11) This book is intended as an introductory textbook for historical linguistics courses, and assumes only that readers will have had an introduction to linguistics. It is hoped that linguists in general and others interested in language-related matters will also find things of interest to them 
in this book, though it is primarily intended for historical linguistics who have little background. (AL 16)

(12) This book was primarily designed to serve students and instructors in aviation law classes at the university, college, and community college levels. The Council on Aviation Accreditation (CAA) Accreditation Standards Manual requires that most undergraduate and graduate programs in aviation cover national and international aviation law and regulations. The content of this book was specifically selected to meet CAA's accreditation standards for the typical aviation law course. (Law 1)

(13) These chapters summarize the current state-of-the-arts studies in the two fish models (particularly in the zebrafish) and focus in particular on the molecular aspects of development. We hope that this book will be a valuable reference for students to learn basic aspects of the two fish models as well as for researchers to look for resources in zebrafish and medaka research (Bio 12)

(14) In the process of reconsidering established corporate ethics management practices, I also have to beg the patience of my practitioner audience, who may feel that I really did not need that much philosophical justification to make my point. Such objections are certainly understandable, but this book is also an attempt to involve my graduate students and my colleagues in a conversation (there are, of course, many others) that I truly believe makes what we do in philosophy exciting. It wants to restore us to our role as public intellectuals who care deeply about the realities navigated by those without the luxury of living primarily as readers, writers and teachers. The role of public intellectuals relies on the ability, and willingness, of both audiences to translate. Practitioners have to share their questions, and their answers, and scholars have to relate their insights into how the history of thought informs our options in the present and in the future. (BA 15)

It is important to note that identifying the audience was carried out either explicitly as in the previous examples, or indirectly and implicitly as shown in example (15).

(15) We believe that our online format has several things going for it. First, an online text can be accessed from any browser in the world, so a student (or any other reader) can gain access to the book at anytime from anyplace. But why put the Internet in the spotlight, why not some other networking technology such as ATM? Most computer networking students have had already significant "hands on" experience with the Internet (e.g., surfing the Web and sending e-mail at the very least) before taking a course on computer networks. We have found that modern-day students in computer science and electrical engineering, being intensive users of the Internet, are enormously curious about what is under the hood of the Internet. Thus, it is easy to get 


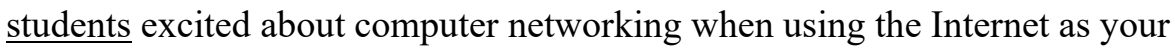
guiding vehicle.

An early emphasis on application-layer issues differs from the approaches taken in most other texts, which have only a small (or nonexistent) amount of material on network applications, their requirements, application-layer paradigms (e.g., client/server), and the application programming interfaces (e.g., sockets). Studying application-layer protocols first allows students to develop an intuitive feel for what protocols are (the role of message exchange and the actions taken on events) in the context of network applications (e.g., the Web, FTP and e-mail) which they use daily.

This textbook also contains material on application programming development - material not covered in depth by any introductory computer networks textbook. (While there are books devoted to network programming, e.g., the texts by Stevens, they are not introductory networking textbooks.) There are several compelling reasons for including this material. First, anyone wanting to write a network application must know about socket programming - the material is thus of great practical interest. Second, early exposure to socket programming is valuable for pedagogical reasons as well - it allows students to write actual network application-level programs and gain first-hand experience with many of these issues involved in having multiple geographically distributed processes communicate. We present the material on application programming in a Java context rather than a $\mathrm{C}$ context, because socket programming in Java is simpler, and allows students to quickly see the forest through the trees.

This text identifies fundamental networking issues as well as approaches towards addressing these issues. We believe that the combination of using the Internet to get the student's foot in door and then emphasizing the issues and solution approaches will allow the student to quickly understand just about any networking technology. (CS 1)

Finally, it is important to note that Move 3 could merge with Move 2 as in the following example:

(16) We have written Aviation Law in order to present the unique interaction of the law and aviation. While we speak to rudimentary international aviation law subjects, we suggest those interested in an in-depth study of international law refer to International Aviation Law: A Practical Guide, which is also published by Ashgate. Our primary goal is the publication of a textbook that provides an introduction to aviation law appropriate for the education of college-level students at the undergraduate and graduate levels as well as practitioners interested in a basic primer on aviation law subjects. The structure of the text provides the instructor with many options. (Law 17) 


\section{Move 4 Outlining organization}

This move was the most predominant component across the disciplines. It was employed in all of the 20 prefaces in law and computer sciences disciplines, and in 19 of the prefaces in the rest of disciplines. Through this move, writers specify the scope of the book, highlight the content of the book by indicating its features and characteristics, and/or provide an outline for the chapters and sections. This move has a scale of explicitness. In example (17), the organization of the book is explicit, as the author included a subtitle chapter format, listed the chapters in order, and provided a short outline of each chapter. Furthermore, the authors enhanced the organization through using visual aids by creating bulleted points.

\section{(17) CHAPTER FORMAT}

Recent case law has been incorporated to provide a better view of the current position of courts across the nation. Chapter features include the following:

- A Chapter Outline provides an introduction to the major topics that will be addressed

-Chapter Objectives at the beginning of each chapter focus students' attention on the main elements the student will learn.

- New Hypothetical Applications are interspersed through each chapter to illustrate chapter concepts. Points for Discussion follow the applications and provide a springboard for class discussion.

- Longer Edited Cases, most of them new to this edition, are followed by questions that encourage students to consider the major issues in each case.

- Assignments Throughout Each Chapter, the majority of which are new to this edition, test students' knowledge by asking them to apply the chapter material.

- Ethical Considerations and Ethical Circumstances in each chapter provide insight to the legal issues presented.

- A chapter Summary ends each chapter with a brief review of the main points covered.

- Key Terms are set in boldface type and defined in the margin where they first appear within the chapter. For easy review, each chapter also ends with a list of the key terms found in the chapter.

- Review Questions follow the chapter material, which allow students yet another opportunity to review the chapter content.

- Helpful Web Sites connect the text material to the most current resources (Law 14)

In example (18), the organization of the book was not explicit enough, as the authors referred to the content of the book by using verb phrases like are described, 
are discussed, approached as, is followed, is concluded, and are supported to help readers to follow.

(18) We decided to treat a representative cross section of heterocyclic ring systems in a conventional arrangement. For these heterocycles, structural, physical and spectroscopic features are described, and important chemical properties, reactions and syntheses are discussed. Synthesis is consequently approached as a retrosynthetic problem for each heterocycle, and is followed by selected derivatives, natural products, Pharmaceuticals and other biologically active compounds of related structure type, and $\underline{\text { is }}$ concluded by aspects of the use in synthesis and in selected synthetic transformations. The informations given are supported by references to recent primary literature, reviews and books on experimental chemistry. (Chem 6)

\section{Move 5 Acknowledging contributions}

This move was used by authors to express gratitude to those who contributed to the writing or publishing of the book as well as colleagues, students, assistants, and family members. This move was the least to be employed in the disciplines with some variations. It was used the most in computer sciences and law prefaces, and appeared less common in the other disciplines, particularly in business administration and chemistry prefaces. In some prefaces, the acknowledgment was written in a subtitle within the preface section. As indicated in Table 4, computer sciences prefaces markedly used a separate section within the preface for the acknowledgements.

Table 4. The inclusion of Acknowledgment as a subtitle in the preface sections, according to discipline

\begin{tabular}{|l|ll|l|l|}
\hline & $\begin{array}{l}\text { No. } \\
\text { Acknowledgements } \\
\text { subtitle }\end{array}$ & $\begin{array}{l}\text { of } \\
\text { in }\end{array}$ & Out of & $\%$ \\
\hline AL & 4 & 11 & 36.4 \\
\hline BA & 3 & 8 & 37.5 \\
\hline LAW & 1 & 16 & 6.3 \\
\hline CS & 13 & 17 & 76.5 \\
\hline Chem & 2 & 9 & 22.2 \\
\hline Bio & 3 & 11 & 27.3 \\
\hline
\end{tabular}

It is important to note that some textbooks opted to include the Acknowledgement in a separate section outside the preface section. In this case, these separate sections were not examined as the focus here was on the preface. This methodology was also adopted in Azar (2012). 


\subsection{Features found in the preface sections}

There were components, although some of which could be merged with rhetorical moves, that were preferably treated separately. In Table 5, the cases of these components were divided into two groups. The first refers to soft disciplines in the study (i.e. applied linguistics, business administration, and law). The second group, on the other hand, refers to hard disciplines (i.e. computer sciences, chemistry, and biology). It is clear that the use of opening statements, signature, titles, websites, tables or figures, photos, and wishing statements were more predominant in hard disciplines. Alternatively, only requests of feedback and personal statements were more common in soft disciplines.

Table 5. Features found in preface sections in soft vs. hard categories

\begin{tabular}{|l|l|l|}
\hline Features & Soft disciplines & Hard disciplines \\
\hline Opening & 2 & 6 \\
\hline Signature & 22 & 38 \\
\hline Titles & 7 & 18 \\
\hline Website & 3 & 16 \\
\hline Feedback & 5 & 3 \\
\hline Tables/ Figures & 2 & 4 \\
\hline Photo & 0 & 3 \\
\hline Personal & 6 & 3 \\
\hline Wishing well & 3 & 5 \\
\hline Total & 50 & 96 \\
\hline
\end{tabular}

Table 6. Features found in preface sections in each discipline

\begin{tabular}{|l|l|l|l|l|l|l|}
\hline Features & AL & BA & LAW & CS & Chem & Bio \\
\hline Opening & 0 & 2 & 0 & 4 & 1 & 1 \\
\hline Signature & 5 & 7 & 10 & 8 & 14 & 16 \\
\hline Titles & 1 & 5 & 1 & 12 & 2 & 4 \\
\hline Website & 0 & 0 & 3 & 13 & 2 & 1 \\
\hline Feedback & 1 & 0 & 4 & 2 & 1 & 0 \\
\hline Tables/ Figures & 1 & 1 & 0 & 4 & 0 & 0 \\
\hline Photo & 0 & 0 & 0 & 1 & 1 & 1 \\
\hline Personal & 3 & 3 & 0 & 1 & 1 & 1 \\
\hline Wishing well & 1 & 1 & 1 & 0 & 3 & 2 \\
\hline Total & 12 & 19 & 19 & 45 & 25 & 26 \\
\hline
\end{tabular}

The first component is opening statements that mostly contained sayings and quotes from outside sources, as exemplified in example (19) and example (20). According to Table 6, computer sciences included four cases, while business administration had two cases, and finally chemistry and biology prefaces had one. 
(19) In the United States, there is a saying among career politicians. "You're not really an incumbent until you win your first re-election." So, in writing textbooks, one is not at all confident of having made much of a contribution after only one edition. (Bio 13).

(20) The most beautiful thing we can experience is the mysterious.

It is the source of all true art and science.

Albert Einstein, What I Believe, 1930. (CS 9, italics are in the source)

The second characteristic was the signature. Biology prefaces showed the highest frequency of using this component with 16 cases out of 20 , followed by chemistry with 14 cases, and half of law prefaces. Regarding the use of titles, tables or figures, and website links, however, computer sciences stood alone in preferring to use these components. Law prefaces employed the feature of requesting feedback from readers the most, while concluding with wishing was found in chemistry prefaces. Finally, the use of personal statements was seen three times in applied linguistics as well as in business administration and chemistry prefaces, as exemplified in examples (21), (22), and (23), respectively. These extracts can be associated with Move 1: Establishing the needs of the readership. In explaining this move above, I have shown that it was used occasionally to provide background knowledge and information about the topic. With the personal statements, it can be added that it functionally helped to provide background information about the authors, which may reflect their promotion intentions.

(21) The first edition of this book was written while I was teaching in an English university. Since then, I have moved to the English department at Montpellier University, in France. While I always had non-native speakers of English in my classes at Newcastle University, most of my students were native speakers of English; now, the vast majority of my students are not native speakers of English. Most are French, but there are also Spanish, Portuguese, Greek, German, Dutch, Polish, Russian and Bulgarian students, among others. The book has changed as a result: it is more orientated towards learners of English as a foreign language, but it is still useful for native speakers, I believe. (AL 4).

(22) Originally from Longford, Ireland, I started work as a newspaper boy in Phoenix, Arizona, where I learned the concept of credit risk when collecting accounts receivable. Each delivery boy was his own independent operator, buying newspapers from the Phoenix Gazette and selling them to subscribers - something not understood by the subscriber on my route who had an especially high rate of default. At UC Berkeley as an undergraduate, I worked in restaurants and the library. At the University of Chicago, I benefited from a scholarship to the Ph.D. program in economics where I had the great fortune of having Nobel Laureate Robert Mundell as my Ph.D. thesis advisor. Upon graduation, I held teaching positions at Harvard University, at the University of Florida, in South Carolina, and at Columbia 
University. I now teach and advise on international business at the University of Miami and at Hunan University, Changsha, China. I also do economic impact reports for projects such as Rivertown, a condominium complex in Miami, the Miami Performing Arts Center, the School of Medicine of the University of Miami, and The Miami Partnership, a civic center revitalization project. The latter applies net present value calculations - the time value of money, using the cost of borrowing of Miami-Dade County. As a consultant to UBS Warburg, I had the opportunity to work with Michael Gavin, Managing Director, on the underwriting of sovereign debt in emerging markets in 2002 and 2003. It has also been a privilege to teach courses in Cameroon and the Ivory Coast, Africa, in Paris at the Université de ParisDauphine, at the Université d'Auvergne, France, in Mexico at ITAM, Mexico City, in Costa Rica, Peru, and at IDEM, Uruguay, in Latin America. As a consultant, I participated in World Bank finance and trade missions to Mongolia, Uzbekistan, Ecuador, Peru, Cameroon, Kenya, Malawi, and Sénégal. In recent years, I have been teaching finance and trade at Hunan University, China, as well as doing joint research with colleagues there. (BA $11)$.

(23) Both of us have many years of experience in teaching introductory general chemistry at the university level, but each of us has certain skills and experiences that will be of special help in the presentation of the chemistry material in this book. Richard "Doc" Langley has taught high school chemistry and has been a grader for the AP Exam chemistry free-response questions for years. John Moore has years of experience teaching chemistry to both public school teachers and students and is the author of Chemistry for Dummies. We are also the coauthors of 5 Steps to a 5: AP Chemistry. We have tried to present the material in such a way that it is understandable and to provide you with some hints and tips to make your studying and learning the material more effective. (Chem 5)

\section{Discussion and conclusion}

The results of this study suggest that Announcing objectives (Move 2) and Outlining organization (Move 4) are common in textbook prefaces, regardless of the kind of discipline. These results resemble those reported in Azar (2012) but are different from those found in Kuhi (2008), especially with the high frequency of Move 4 (outlining organization) that was optional in Kuhi's study. The other moves occurred more in some disciplines and less in others. Specifically, Move 1 (Establishing the needs of the readership) was more predominant in business administration, law and biology prefaces. Move 3 (Identifying audience) was more common in computer science prefaces. Finally, Move 5 (Acknowledging contributions) was more frequent in computer science and law prefaces. These disciplinary variations were not found in Abdollahzadeh and Salarvand (2013), who 
examined three academic disciplines: management, metallurgy and mathematics. In fact, in the present study the disciplinary variations in terms of the rhetorical structure were not found when disciplines were grouped into soft and hard categories.

However, this was not the case when the present study went further to examine particular features found in the prefaces. The employment of opening statements, signature, titles, websites, tables or figures, photos, and wishing statements were more common in hard disciplines, while other features such as requesting feedback and providing personal statements were more predominant in soft disciplines. In particular, computer science prefaces had a clear preference to use subtitles and provide website links. In addition, chemistry and biology textbooks showed more tendency to conclude their prefaces with signatures. The results of the present study suggest that more studies to examine cross-disciplinary similarities and differences are necessary.

As already found in Luzón (1999), Abdollahzadeh and Salarvand (2013) and Azar (2012), the preface sections of textbooks included several cases that reflect the authors' promotional and persuasive intentions. For instance, authors of preface sections used the second person pronouns more frequently to engage with readers. In addition, writers identified deficiencies in previous works and presented their books as solutions to them. As pointed out by Azar (2012), "Functionally, writers use these major moves to attempt to establish a need for their work in the current competitive academic setting, and show their orientations and describe their work positively in order to promote them as products" (p. 161). The configuration of promotional purposes in preface sections was also reported in Al-Zubaidi and Jasim (2016), who examined prefaces from linguistics books in English and Arabic, which indicates that this promotional purpose occurs across languages as well as across disciplines.

To increase knowledge of preface sections, more genre-based studies are indispensable. Indeed, the results of this study should be useful for ESP teachers to have a better understanding of this genre. This will aid them in designing and teaching textbooks, according to the conventions of their discourse community. Additionally, teachers can raise students' awareness and consciousness about the rhetorical patterns of preface sections. Hence, they can better read, criticize, and write academic texts based on the conventions of the genre.

Finally, one limitation of the present study is that the size of the compiled corpus might not be large enough to generalize the findings. Therefore, more studies on the chosen disciplines in this study are recommended.

Hmoud S. Alotaibi

Shaqra University, KSA

ORCID Number: 0000-0002-7191-5844

Email: halrwais@su.edu.sa 


\section{References}

Abdollahzadeh, Esmaeel and Salarvand, Hossein. (2013). 'Book prefaces in basic, applied and social sciences: A genre-based study.' World Applied Sciences Journal, 28, 18-26.

Alotaibi, Hmoud and Hamid Arabi. (2020). 'Taking authorial stance in Arabic research articles introductions.' International Journal of Arabic-English Studies (IJAES), 20(2), 41-62.

Al-Zubaidi, Nassier and Tahani Jasim. (2015). 'Preface sections in English and Arabic linguistics books: A rhetorico-cultural analysis.' Advances in Language and Literary Studies, 7(2), 25-32.

Asghar, Samina, Zobina Asghar and Muhammad Mahmood. (2015). 'A genre analysis of preface sections of textbook.' Journal of Education and Practice $6(7), 58-63$.

Azar, Ali. (2012). 'The self-promotion of academic textbooks in the preface section: A genre analysis.' Journal of the Spanish Association of AngloAmerican Studies, 34, 147-65.

Bhatia, Vijay K. (1993). Analyzing genre: Language use in professional settings. London: Longman.

Hyland, Ken. (2005). Metadiscourse: Exploring Interaction in Writing. London: Continuum.

Ji, Weining and Wei Wang. (2016). 'The 45 years' evolution of a genre: Commodification of the university textbook prefaces in China.' Critical Approaches to Discourse Analysis across Disciplines, 8(1), 1-22.

Kuhi, Davud. (2008). 'An analysis of move structure of textbook prefaces.' Asian ESP, 7, 63-78.

Luzón, Maria Jose. (1999). 'An interactive genre within the university textbook: the preface.' Journal of Technical Writing and Communication, 29(4), 409429.

Mohsenzadeh, Hoda. (2013). 'Rhetorical move structure of literature book prefaces in English and Persian.' Mediterranean Journal of Social Sciences, 4, 317-323.

Munalim, Leonardo and Rachelle Lintao. (2016). 'Metadiscourse in book prefaces of Filipino and English authors: a contrastive rhetoric study.' Imanager's Journal on English Language Teaching, 6(1), 36-50.

Swales, John. (1990). Genre analysis: English in academic and research setting. Cambridge: Cambridge University Press.

Swales, John. (2004). Research genres: Explorations and applications. Cambridge, UK: Cambridge University Press. 